\title{
González Ponciano, Jorge Ramón y Miguel Lisbona Guillén (coords.), 2009, México y Guatemala: entre el liberalismo y la democracia multicultural —azares de una transición política inconclusa-, México: UNAM (Instituto de Investigaciones Filológicas e Instituto de Investigaciones Antropológicas).
}

L as 322 páginas que conforman México y Guatemala: entre lliberalismo y la democracia multicultural llevan al lector entre los azares e indefiniciones de las transiciones políticas en ambos países o, para decirlo en los términos de W. Benjamin en Para una crítica de la violencia (1921), entre la fortuna y el estupor. La fortuna, por asistir a discusiones jugosas a través de doce ensayos que dan cuenta de las realidades políticas, los dilemas de la ciudadanía y las trampas de las transformaciones democráticas en Guatemala y México, en este último caso, con énfasis en Chiapas. También, el estupor porque las situaciones que vivimos, y describen los autores, sean aún posibles y definan el "estado de emergencia" que caracteriza a nuestras sociedades.

Jorge Ramón González Ponciano y Miguel Lisbona Guillén, los coordinadores de la obra, la presentan como fruto de un debate con cierta informalidad política y académica para invitar al lector a aprovecharla. Dicho debate se inició con la exposición de los textos en un coloquio celebrado a fines de agosto del 2005 en la ciudad de San Cristóbal de Las Casas, y continuó con la revisión posterior de sus autores al cruzar experiencias de vida, académicas y políticas, que enriquecen la agenda de debate intelectual y político. Esto es más relevante en la condición de algunos colaboradores guatemaltecos de intelectuales indígenas mayas.
Sin duda, el libro se sitúa como una valiosa novedad bibliográfica por dos virtudes fundamentales. La primera, ser resultado de un diálogo académico entre intelectuales de México y Guatemala que buscan, como dice una de las colaboradoras, Xóchitl Leyva, mirar a trasluz las realidades de ambos países para comprender procesos históricos compartidos y la cultura común; asimismo, piensan a contrapelo las tensiones ideológicas y políticas que atraviesan a los actores sociales, para criticar las mismas categorías utilizadas para dar cuenta de ellos y de los procesos sociopolíticos. De esta manera se evidencia la segunda virtud del texto, a saber: definir el talante de un ejercicio crítico sobre el propio trabajo intelectual, de los investigadores que muchas veces seguimos ciertas modas conceptuales, sin cuestionar su anclaje en la episteme del sistema social donde se forjaron, sin siquiera resignificarlas en nuestros contextos.

El libro se estructuró en tres partes: "Historia y cultura," "Política y pueblos indígenas" y "Dilemas de la ciudadanía". Tres ensayos abren el horizonte de la discusión, son escritos por Miguel Lisbona Guillén, Andrés Fábregas Puig y Mauricio Tenorio Trillo. Todos cuestionan viejas formas de entender y abren varias perspectivas para trabajos futuros y para la comprensión del estado de cosas en ambos contextos nacionales y en sus zonas de contacto. Por ejemplo, Lisbona hace una 
crítica mordaz a los reduccionismos de los conceptos de cultura e identidad, que los hipostasian en tanto permanencia e inmovilidad, instalando la paradoja entre comunitarismo culturalista y construcción de ciudadanos acríticos con su propias culturas. Fábregas, aguza su mirada antropológica sobre la frontera entre los dos países para dar cuenta de procesos sociales más amplios desde una perspectiva histórica y muy actual, de los juegos de intereses concurrentes en los ámbitos regionales de negociación, así como para definir una agenda concreta de temas por analizar más allá del contrapunto de oposiciones que enfatiza los límites políticos nacionales. Por su parte, Tenorio Trillo desmonta desenfadadamente el "mito del mestizaje" como cemento ideológico para la integración, con inclusiones excluyentes, de la sociedad nacional bajo el pacto liberal-burgués posrevolucionario.

El resto del libro está formado por seis ensayos sobre Guatemala y tres sobre México. La riqueza de todos amerita una atención especial porque abrevan discusiones sustantivas. Tal es el caso de los trabajos de José Woldenberg y Magdalena Gómez, cuyo contrapunto interpretativo sobre los avatares de la transición política mexicana ilustra el horizonte de discusión en medio del desencanto democrático. Woldenberg enfatiza, basándose en su experiencia, en la construcción de ciudadanía por la vía de la participación electoral, mientras que Gómez amplía el debate en torno al ejercicio de los derechos sociales, civiles y culturales a partir del reconocimiento efectivo de la pluralidad, de los derechos colectivos y las formas de representación indígenas. En este sentido, cuando se piensa en la forja de ciudadanía en Guatemala y en México, hay que subrayar las situaciones estructurales que han dimensionado su adjetivación en los dos países: 1) la pobreza y 2) la resistencia. Ambas someten a múltiples tensiones a la democracia, situándola entre la incertidumbre sobre sus límites, el uso de la violencia de estado como principal recurso de gobernabilidad -en detrimento y franca violación del estado de derecho y las garantías individuales - y la impugnación por la ciudadanización de la política promovida por los movimientos sociales, los sentimientos de pertenencia comunitaria, los vínculos sociales y la convivencia.

Entre los dilemas discutidos en los diferentes casos tanto en México como en Guatemala, se muestra el exilio común en que vivimos: fuera de la condición cívica o la condición de ciudadano, sin ejercer derechos, ni obligaciones; sin mejoras en las condiciones vida, ni en la propia condición humana. Tal degradación de la ciudadanía refiere situaciones estructurales de exclusión de la mayoría de la población lo que hace una verdadera quimera construir una ciudadanía autónoma, activa y responsable.

En general, los trabajos invitan a muchas reflexiones entre las que no quisiera pasar por alto las relativas a la crisis del sujeto liberal y la fragilidad del tejido social en ambos países. Como sabemos, la crisis del sujeto liberal ha sido cíclica y refiere a las paradojas del liberalismo, las quiebras de la concepción del sujeto de la modernidad, a su crisis de valores que ha oscilado entre la noción individualista y abstracta de libertad y el abandono de valores de igualdad y solidaridad. El sujeto dueño de la razón, autocentrado, centro del universo, ya no es un cimiento para la búsqueda de identidad. El desgarramiento entre pensar y actuar del sujeto liberal - blanco, propietario y letrado-y el mundo moderno - homogéneo, abstracto, global, totalizador, controlador y disciplinador-, adquirió una más limitada capacidad de respuesta ante la oleada neoliberal porque, al margen de las consignas pluralistas y los rituales de participación electoral como muestra irrisoria de ejercicio de los derechos políticos, la mayor concentración de poder, de medios, ha propiciado una mayor corrupción de los códigos morales liberales y de la ética del poder, tan en sintonía con el conservadurismo político, hasta reforzar la violencia como central en las relaciones de dominación. El llamado adelgazamiento del estado supuso una organización represiva del aparato gubernamental. En 
México esto es clarísimo y en Guatemala, lo evidencian varios trabajos del libro que reseñamos: como el de Demetrio Cojtí Cuxil, al dar cuenta del desfase entre discursos y realidades de la vida política de los guatemaltecos; el ensayo de Irma Alicia Velásquez, al presentar la represión de familias man que reivindican sus tierras; y, el de Rigoberto Quemé Chay, al analizar el modelo político monocultural y paternalista del estado guatemalteco, los pecados capitales de sus partidos - centralismo, monoculturalismo, autoritarismo, "cortoplacismo", corporativismo, ilegitimidad, demagogia-, las expresiones de lucha indígena, la emergencia del movimiento maya y un pensamiento político con propuestas para articular la transformación de la realidad. El propio Quemé es muy crítico con aquellos intelectuales indígenas, "libre pensadores", que “...no se comprometen con nada ni con nadie. Están encerrados en una burbuja de cristal que los separa de la práctica política" (p.188).

La fragilidad de los tejidos sociales, la debilidad del vínculo social, refiere inclusiones que naturalizaron la exclusión de amplios sectores sociales hasta los extremos de inseguridad humana, hasta hacer inhabitable la sociedad actual. A las relaciones de dominación históricas que racializaron las relaciones sociales para, como bien dicen Cojtí y González, devalorizar la fuerza de trabajo indígena y asegurar la dominación social y política, se sumó la inmiseración galopante por las políticas públicas que contribuyeron a mercantilizar prácticamente todas las relaciones sociales. Las promesas del liberalismo constructor del estado nacional se truncaron. Mientras que la igualdad se ahogaba en la diferenciación y la jerarquización de las relaciones sociales, la libertad se limitó al individualismo posesivo, insolidario y hedonista y la competencia (individual y corporativa). Quizás por ello, la solidaridad o reciprocidad son nuevamente la utopía de los nuevos comunitarismos. Las críticas a las ideologías del comunitarismo - "posrománticas," como dice Lisbona-, como engañosas visiones etnocéntricas sobre las formas de estar, habitar y nombrar las cosas, invitan a un descentramiento de las categorías dominantes de etnicidad y multiculturalismo en la construcción de identidades que desplacen el etnocentrismo y resalten lo verdaderamente nuevo, a saber: los cambios en la identidad del ser social, las ligazones éticas trabadas en la cultura para ser una sociedad, es decir, las causas comunes como formas morales de compromiso y responsabilidad, y espacios de solidaridad e interacción.

Varios capítulos nos muestran el carácter estructural de la desigualdad y las circunstancias indignantes que conlleva, como a la propia venta de naturaleza y cultura, mientras recuperan una serie de experiencias de resistencia de la ciudadanía que van desde las formas de participación en la vida política hasta la movilización colectiva a través de diversos recursos para la protesta social. Por ejemplo, contra las mineras transnacionales a través de un plebiscito en Sipakapa o para reclamar tierras a través de marchas y plantones en Guatemala, como nos muestran Irma Otzoy y Velázquez Nimatuj en sus respectivas contribuciones. Estas experiencias de resistencia, de lucha, aluden a formas emergentes de acción cuando se ve amenazada la reproducción social y la misma supervivencia por las transformaciones en la estructura agraria y en las formas de propiedad de la tierra; asimismo, a búsquedas de soluciones que marcan la diferencia al tratar de evidenciar y suturar el déficit de legitimidad de los discursos dominantes, así como la labilidad ideológica de las élites dominantes y las estrategias represivas de los estados como vía de gestión de los conflictos. También, se enuncian otros desafíos de la ciudadanía a partir de la intensa dinámica migratoria y de la emergencia de identidades transterradas; mismos sobre los que Alfonso Arrivillaga ofrece un exquisito ejemplo a través de un estudio de la comunidad garífuna, su movilidad espacial, la diáspora, los vínculos como estrategia de supervivencia y su ciudadanía transnacional. 
El capítulo de Leyva es muy sensible a esta recuperación de las experiencias de los movimientos sociales y la construcción de ciudadanías diferenciadas en Chiapas a partir de un ejercicio de memoria que rescata discursos racializados y racialistas explicativos de la emergencia de la violencia racial. La autora subraya que las identidades construidas sobre un memorial de agravios nutrido de la imagen de antepasados oprimidos y asesinados, cuentan con una fuerza que trabaja para fortalecer el "nosotros"; mientras, soslaya cómo ese memorial actúa, al mismo tiempo, contra "nosotros" porque el "duelo", como contexto de afirmación de causas comunes, desvalora interiormente al sujeto, lo desmoviliza — sobre todo, a sus descendientes que no ven un escenario ideal diferente-, propiciando involuntariamente lo que se quiere evitar: su "clausura instrumental". Los vínculos, las formas de relación social, entre identidades no etnocentradas, deben actualizarse sobre la base de la ambivalencia radical entre el miedo y la esperanza, el recuerdo y el olvido.

En esta última tesitura González Ponciano explora la relación entre estado, cultura y ciudadanía en Guatemala. González cierra el libro a través de la metáfora excepcional de una novela de ficción que desde 1950 profetizaba la espiral de miedo, discriminación y racismo desatada con la elección de un presidente indígena en el 2000, así como la reproducción de ese imaginario entre la población al actualizarse lo que llama los "marcadores de estatus o poder". El contrafáctico histórico o la profecía por cumplirse, según el emplazamiento temporal desde donde se mire, evidencia cómo sobre las estructuras de la desigualdad social se funde una compleja diferenciación cultural, basada en la raza, la etnia, la clase, el género y la generación, que persiste en las mentalidades con una profundidad histórica difícil mas no imposible de fracturar.

De esta manera, a pesar del escenario de cadenas de conflicto que conforman la historia del hombre dominado - "la Vergüenza", de la que hablaba Nietzsche a través de Zaratustra-, no deben dejar se ponerse las miras en la creación de un verdadero estado de emergencia, porque como invitaba a pensar Benjamin, lo que pasa es que la idea de historia de la cual partimos carece de vigencia. La pregunta es cómo saltar ese continuum de la historia, para crear otro tiempo, con soluciones a las aporías del liberalismo reñidas con la realización conjunta de los ideales modernos, los derechos y deberes ciudadanos. En nuestros respectivos países esto es impensable si no se emprende la reforma integral del estado. Tampoco, si desde las ciencias sociales y las humanidades no se desarrolla una comprensión antropológica de las otras culturas, más intercultural, es decir, relacional y relativa a sus complejas interacciones e influencias mutuas.

El lector interesado constatará que el libro es en sí mismo un augurio de la formación del compromiso intelectual con los que forcejean con la realidad por la articulación de la vida que todos queremos vivir para trascender las situaciones actuales. Sin duda, trabajar por una cercanía académica y personal entre las comunidades intelectuales de ambos lados de la frontera, es algo medular que nos compete a todos para que, como sugiere el diseño para la portada de Samuel Flores, las ensoñaciones de nuestros pueblos no caigan en morrales huecos, ni en cajitas que los atrapen y frustren permanentemente. 